\title{
Prophylactic antibiotics for hysterectomy and cesarean section: amoxicillin-clavulanic acid versus cefazolin
}

\author{
Jyoti Malik ${ }^{1}$, Sibadatta Das ${ }^{2}$, Ashima Das $^{3}$, Pinki Rai $^{3}$ * \\ ${ }^{1}$ Department of Obstetrics and Gynaecology, SHKM Govt. Medical College, Nalhar, Haryana, India
${ }^{2}$ Department of Physiology, SHKM Govt. Medical College, Nalhar, Haryana, India
${ }^{3}$ Department of Anatomy, SHKM Govt. Medical College, Nalhar, Haryana, India \\ Received: 09 March 2016 \\ Accepted: 19 March 2016 \\ *Correspondence: \\ Dr. Pinki Rai, \\ E-mail: pinkirai89@gmail.com \\ Copyright: (c) the author(s), publisher and licensee Medip Academy. This is an open-access article distributed under \\ the terms of the Creative Commons Attribution Non-Commercial License, which permits unrestricted non-commercial \\ use, distribution, and reproduction in any medium, provided the original work is properly cited.
}

\begin{abstract}
Background: To compare amoxicillin-clavulanic acid with cefazolin as short term antibiotic prophylaxis in women undergoing hysterectomy and elective casarean section.

Methods: 60 women undergoing hysterectomy were randomly assigned either to $2.4 \mathrm{~g}$ intravenous amoxicillinclavulanic acid (AMX/CL) or $2 \mathrm{~g}$ cefazolin $30 \mathrm{~min}$ before hysterectomy. 122 women delivered by elective cesarean were randomized to a single dose of either of above antibiotics at cord clamping. Each patient was assessed daily until discharge for evidence of febrile status and the presence of infection at the operative site and urinary tract.

Results: Infectious morbidity was found in $11 \%$ and $12.5 \%$ of hysterectomy patients in AMX/CL and cefazolin cases respectively. 10 women had post-cesarean infections (6 AMX/CL, 4 cefazolin, $\mathrm{p}=0.51$ ).

Conclusions: Broad spectrum amoxicillin-clavulanic acid was not superior to cefazolin in prevention of postoperative infection when given as prophylaxis in hysterectomy and elective cesarean section.
\end{abstract}

Keywords: Antibiotic prophylaxis, Hysterectomy, Abdominal, Vaginal, Cesarean delivery, Elective, Emergency

\section{INTRODUCTION}

Hysterectomy and cesarean sections are the most commonly performed operations among inpatients in our institution (SHKM Govt. Medical College, Nalhar). The two most frequent complications of these surgeries are fever and operative site infection. Many studies have been published in recent years stressing the need for antimicrobial prophylaxis in hysterectomy. Women undergoing elective cesarean section are considered low risk populations. Although serious infectious complications are uncommon in this group, a literature survey demonstrated that prophylactic antibiotics significantly reduced the risk of endometritis and wound infection. $^{2-4}$

Hysterectomy is performed through a contaminated field and it is the mixed aerobic and anaerobic bacterial flora of the lower genital tract that serves as a reservoir for most of the pathogens associated with post-operative sepsis. The use of prophylactic antibiotics in the hysterectomy and cesarean section in our institution is not standardized and is determined by the consultant in charge of the case. The most commonly used regimen is to give the three doses of cefazolin intravenously. However cefazolin is not active against anaerobes which are the potential pathogens in the vaginal flora. So theoretically cefazolin due to its limited spectrum does not meet the guidelines as an ideal agent for prophylaxis.

Amoxycillin and the beta-lactose inhibitor clavulenic acid have been shown to have an increased spectrum of activity against a wide variety of aerobic and anaerobic bacteria. Against this background, a prospective trial was performed to compare amoxicillin-clavulenic acid (AMX/CL) with cefazolin in preventing sepsis following hysterectomy and elective cesarean section. 


\section{METHODS}

Women who were scheduled to undergo hysterectomy for benign diseases and elective cesarean deliveries were enrolled in this trial. The cesarean was considered elective if the procedure was performed in absence of labor and before rupture of membranes. The exclusions were made for the patients who gave history of hypersensitivity to penicillin or cephalosporin; or signs of pre-existing infections and those who had received antibiotic therapy within the last seven days prior to surgery. The patients received information concerning objectives of the trial prior to surgery and written consent was obtained. The study protocol was approved by the ethical committee of the hospital. Patients were randomly allocated to one of the two regimens: amoxicillinclavulanic acid $2.4 \mathrm{~g}$ (Augmentin, GlaxoSmithCline) and cefazolin 2 g (Reflin, Ranbaxy). Study medication was given intravenously at the time of induction of anesthesia (15-30 min before incision). In the case of extensive blood loss $(>1000 \mathrm{ml})$ or a surgical duration of longer than 3 hours, a second dose of antibiotic was administered as a single dose immediately after clamping the umbilical cord. Surgery was performed by the staff, gynaecologists. In women who underwent vaginal hysterectomy for prolapsed, the catheter was retained for two days.

After surgery, each patient was assessed daily until they were discharge from the hospital. Two main outcome measures of this study were fever and infection. Febrile morbidity was defined as a temperature of $\geq 100.40{ }^{0} \mathrm{~F}$ recorded on at least two successive occasions 6 hours apart, excluding the $1^{\text {st }} 24$ hours after surgery. Infection of one or more sites was diagnosed by clinical symptoms and signs and/or laboratory tests. The infections included abdominal wound infection, pelvic cellulitis, vaginal cuff infection or urinary tract infection (both symptomatic and asymptomatic). Pelvic cellulitis was diagnosed by the trial of increasing lower abdominal discomfort, temperature elevation and increasing tenderness to gentle deep lower abdominal palpation. The patients in cesarean section group up were followed up for the development of endometritis (fever, uterine tenderness and offensive lochia). All the women were evaluated for six weeks postoperatively in order to determine any late morbidity.

Differences in continuous variables were analyzed with student t-test for normally distributed data and the Mann Whitney test for collected data. Differences in discrete variables were analyzed by Uriz Yates corrected chi square test with one degree of freedom. A p-value of $<0.005$ was considered significant.

\section{RESULTS}

The study group consisted of 182 patients from April 2004 to September 2005 who underwent hysterectomy $(n=60)$ and cesarean delivery $(n=122)$. The characteristics of study patients are presented in Table 1 .

Table 1: Characteristics of patients in the two surgical groups.

\begin{tabular}{|c|c|c|c|c|c|c|c|}
\hline \multirow{2}{*}{$\begin{array}{l}\text { Sr. } \\
\text { No. }\end{array}$} & \multirow{2}{*}{ Parameters } & \multicolumn{3}{|c|}{ Hysterectomy } & \multicolumn{3}{|c|}{ Cesarean delivery (CD) } \\
\hline & & AMX/CL & Cefazolin & p-value & AMX/CL & Cefazolin & p-value \\
\hline 1 & No. of patients & 36 & 24 & & 55 & 67 & \\
\hline 2 & Mean age (in year) & 47.6 & 43.2 & 0.02 & 28.4 & 27.1 & 0.05 \\
\hline 3 & BMI & 23.7 & 23 & 0.5 & 24.5 & 24 & 0.3 \\
\hline 4 & AssociatedSystemic disease & 6 & 4 & 0.05 & 5 & 2 & 0.29 \\
\hline 5 & Type of surgery & $\begin{array}{l}\text { TAH } \pm \text { BSO } \\
(\mathrm{n}=24) \\
\text { VH/LAVH } \\
(\mathrm{n}=12)\end{array}$ & $\begin{array}{l}\text { TAH } \pm \text { BSO } \\
(\mathrm{n}=21) \\
\text { VH/LAVH } \\
(\mathrm{n}=3)\end{array}$ & & $\begin{array}{l}\text { Primary } \\
C D=32 \\
\text { Repeat } \\
C D=23\end{array}$ & $\begin{array}{l}\text { Primary } \\
C D=34 \\
\text { Repeat } \\
C D=33\end{array}$ & \\
\hline
\end{tabular}

Table 2: Risk factors for developing postoperative infections.

\begin{tabular}{|llllllll|}
\hline Sr. & \multirow{2}{*}{ Parameters } & Hysterectomy & & Cesarean & \\
No. & & AMX/CL & Cefazolin & p-value & AMX/CL & Cefazolin & p-value \\
\hline 1 & Mean duration of operation (in min.) & 150.9 & 147.2 & 0.71 & 45.3 & 45.5 & 0.73 \\
\hline 2 & Mean blood loss (in ml) & 441.1 & 508.3 & 0.13 & 567.21 & 523.8 & 0.22 \\
\hline 3 & Mean days of catheterisation & 1.7 & 1.2 & 0.02 & 1 & 1.01 & 0.36 \\
\hline
\end{tabular}


Table 3: Incdence of post-operative infections and Duration of post-operative stay.

\begin{tabular}{|c|c|c|c|c|c|c|c|}
\hline \multirow{2}{*}{$\begin{array}{l}\text { Sr. } \\
\text { No. }\end{array}$} & \multirow{2}{*}{ Parameters } & \multicolumn{3}{|c|}{ Hysterectomy } & \multicolumn{3}{|l|}{ Cesarean } \\
\hline & & $\mathbf{A M X} / \mathbf{C L}$ & Cefazolin & p-value & $\mathbf{A M X / C L}$ & Cefazolin & p-value \\
\hline 1 & $\begin{array}{l}\text { Mean post-operative hospital } \\
\text { stay (in days) }\end{array}$ & 8.6 & 9.5 & 0.27 & 10.6 & 9 & 0.46 \\
\hline 2 & Wound Infection & 2 & 0 & 1 & 3 & 2 & 0.82 \\
\hline 3 & Pelvic Cellulitis & 0 & 1 & 0.84 & - & - & - \\
\hline 4 & Endometritis & - & - & - & 1 & 1 & 1 \\
\hline 5 & Asymptomatic bacteriuria & 2 & 2 & 1 & 2 & 1 & 0.76 \\
\hline 6 & Total Infections & 4 & 3 & 1 & 6 & 4 & 0.51 \\
\hline
\end{tabular}

No Significant differences were found among the two treatment groups with respect to clinical characteristics except the age in women who had hysterectomy. This might be due to the fact that ten subjects with genital prolapsed were included in the AMX/CL group and were significantly older than the comparable cefazolin group. Risk factors for developing post-operative infection are presented in Table 2 .

In the hysterectomy group, 26 subjects received a 2nd dose of antibiotic for massive blood loss and prolonged surgery. Both drugs were very well tolerated. One case of diarrhoea was observed in the AMX/CL group and no side effects were observed with cefazolin.

Six women (10\%) developed febrile morbidity following Hysterectomy. Most of these women received packed cells for decreased hemoglobin postoperatively. None exhibited symptoms or physical findings of clinical infection and none received additional antibiotics. Two patients $(1.6 \%)$ who had undergone cesarean section developed febrile episodes and the fever was caused by congestion of the breasts.

The Table 3 summaries the rates and types of infections observed in two surgical groups. The patients who developed pelvic cellulitis were treated with parenteral antibiotics. Endometritis was reported in two patients who underwent cesarean delivery. In AMX/CL group, the patients responded promptly to oral antibiotics. One lady who had received cefazolin developed late endometritis and rehospitalzed and managed with combination antimicrobial therapy. None of the patients in this study developed post-operative urinary tract infection. Hospital stay was computed begging with the day of surgery. The post-operative hospitalization was similar for both the drugs.

\section{DISCUSSION}

Many of the studies that have supported the development of antimicrobial prophylaxis guidelines are quite old. Moreover, there is a great variation in the use of antimicrobial prophylaxis by surgeons during hysterectomy. Trolo and Kocak have evaluated AMX/CL as prophylactic antibiotic for laparotomic gynecologic surgery. ${ }^{5,6}$ They included clean procedures such as adhexectomy, where prophylactic antibiotics are not indicated. ${ }^{7}$ So, in this study only abdominal and vaginal hysterectomy has been included. A one day point prevalence study performed in this Institution (SHKM GMC, Nalhar) in November 2003 for infectious morbidity following cesarean delivery was found to be $15 \%$. Most of authorities ${ }^{8}$ has suggested that prophylactic antibiotics should be considered for all elective cesarean deliveries in which the combined incidence of endometritis and wound infections exceeds $5 \%$. So, in this study, we decided to administer antibiotic prophylaxis for cesarean patients.

The incidence of febrile morbidity in the hysterectomy group was $10 \%$. This data is consistent with that reported by Chong somachi et al, Hemsell et al believed that febrile morbidity per se does not indicate significant infection and hence, should not be included categorically as a type of post-operative infection. ${ }^{9,10}$ In the Hysterectomy group, we found low overall percentage of post-operative infections in both the antibiotic groups.

Similar data was reported by Cormio et al, Asymptomatic bacteriuria was observed frequently $(5.5 \%$ of AMX/CL group and $8 \%$ of Cefazolin treated patients). ${ }^{11}$

The incidence of post-cesarean infection was low and was similar when compared with other studies. ${ }^{12,13}$ Postcesarean bacteriuria may be further reduced by avoiding routine catheterization. The present study has shown that AMX/CL which has activity against all the potential pathogens was not superior to cefazolin in its ability to prevent infection in these women. If only drug costs are considered, the use of AMX/CL was more expensive.

Recently, another aspect of prophylaxis is to shorten the duration of antibiotic use. For most hysterectomies, a single dose of antibiotics is sufficient. ${ }^{14}$ Current information suggest that additional dose should be given at intervals of twice the half-life of antibiotic to maintain adequate levels throughout the procedure. ${ }^{15}$ Keeping this data in mind, we administered the $2^{\text {nd }}$ dose of antibiotic 4 hours after the initial dose. 


\section{CONCLUSIONS}

This prospective study confirms that antibiotic prophylaxis had a beneficial effect on women undergoing hysterectomy and elective cesarean section. Both the drugs-AMX/CL and cefazolin seems to be equally effective.

\section{Funding: No funding sources}

Conflict of interest: None declared

Ethical approval: Not required

\section{REFERENCES}

1. Hemsell DL. Prophylactic antibiotics in gynecologic and obstetrics surgery. Rev Infact Dis. 1991;13:5821-41.

2. Jamie W, Dff P. Preventing infections during elective C/S and abdominal hysterectomy. Contempt Obstet Gynnecol. 2003;48:60-9.

3. Smaill F, Hofmeyr GJ. Antibiotic prophylacxis for cesarean section. Cochrane Database Syst Rev. 2002:CD000933.

4. Chelmow D. Should patients undergoing low-risk $\mathrm{C} / \mathrm{S}$ receive antibiotic prophylaxis. Contemp Obstet Gynecol. 2006;51:57.

5. Triolo $\mathrm{O}$, Mancuso A, Pantano $\mathrm{F}$. Amoxicillin/clavulanate prophylaxis in gynecologic surgery. Int J Gynaecol Obstet. 2004;85:59-61.

6. Kocak I, Ustun C, Gunkan N. Prophylactic antibiotics in elective abdominal hysterectomy. Int J Gynaecol Obstet. 2005;90:157-8.

7. Bahador A, Roy S. Prevention of post-operative gynecologic infections. In: Mishell DR, Goodwin TM, Brenner PF. Management of common problems in obstetrics and gynecology, $4^{\text {th }}$ Edition. Massachusetts, Blackwell Publishing. 2002;228:31.
8. Chelmow D, Ruchli MS, Huanz E. Prophylactic use of antibiotics for non-labouring patients undergoing cesarean delivery with intact membranes a metaanalysis. Am J Obstet Gynecol. 2001;184:656-61.

9. Chongsomchai C, Lumbiganon P, Thinkhamrop J. Placebo controlled, double-blind, randomized study of prophylactic antibiotics in elective abdominal Hysterectomy. J Hosp Infect. 2002;52:302-6.

10. Hemsell DL, Cunningham FG Kappus S. Cefoxitin for prophylaxis in premenopausal women undergoing vaginal hysterectomy. Obstet Gynecol. 1980:56:629-34.

11. Cormio G, Di Fazio F, Cacciapuoti C. Prospective randomized study comparing amoxicillin-clavulanic acid with cefazolin as antimicrobial prophylaxis in laparotomic gynecologic surgery. Acta Obstet Gynaecol Scand. 2003;82:1130-4.

12. Yip SK, Lan TK, Rogers MS. A studyon prophylactic antibiotics in cesarean section - is it worthwhile? Acta Obstet Gynecol Scand. 1997:76:547-9.

13. Rouzi AA, Khalifa $f, B a$ 'aqueel $H$. The routine use of cefazolin in cesarean section. Int $\mathrm{J}$ Gynecol Obstet. 2000;69:107-12.

14. Duff P. Prophylactic antibiotics for hysterectomy. Contemp Obstet Gynecol. 1997:42:21-6.

15. Sweet RL, Gibbs RS. Antibiotic prophylaxis in obstetrics and gynecology. In: Infectious diseases of the female genital tract, $4^{\text {th }}$ edition. Philadelphia Lippincott. 2000.

Cite this article as: Malik J, Das S, Das A, Rai P. Prophylactic antibiotics for hysterectomy and cesarean section: amoxicillin-clavulanic acid versus cefazolin. Int J Reprod Contracept Obstet Gynecol 2016;5:980-3. 